\title{
Predation ANd Network Based Price Discrimination in Chile
}

\section{Claudio Agostini ${ }^{*} \quad$ Raúl Lazcano $^{\S} \quad$ Eduardo Saavedra $^{\xi}$ Manuel Willington ${ }^{¥}$}

January 2016

\begin{abstract}
This paper uses a model of strategic interaction among firms -that set discriminatory and nonlinear prices- together with public information on prices of the plans marketed by the three major mobile phone companies, to assess the extent to which on-net and offnet price differentials in the plans they offer could represent predatory practices in the mobile telephony market in Chile. The results show that these companies offered plans that could present evidence of predatory practices. Despite the fact that these plans were a small fraction of all the plans mobile phone firms offered they were recently banned by the antitrust authority as they represented a relevant fraction of all traffic.
\end{abstract}

Keywords: Telecommunication network competition, on-net/off-net price discrimination, call externality

JEL Classification: D43, L41, L51, L96

\footnotetext{
*School of Government, Universidad Adolfo Ibáñez. E-mail: claudio.agostini@uai.cl

$\S$ Ministry of Transports and Telecommunication, Chile. E-mail: $\underline{\text { raul.lazcano@subtel.cl }}$

${ }^{\xi}$ ILADES-Universidad Alberto Hurtado. E-mail: saavedra@uahurtado.cl

¥ School of Government, Universidad Adolfo Ibáñez. E-mail: manuel.willington@uai.cl
} 


\section{Introduction}

Many mobile telephony plans offered by telecommunication companies in Chile are characterized by nonlinear and discriminatory prices. That is, the plans usually entail both fixed and per minute tariffs. Discrimination might occur in two dimensions: first, the number of included on-net minutes in the plan is usually larger than the number of included off-net minutes, and second, once included minutes are exhausted the per minute price of on net calls is lower than the one for off-net calls. This discriminatory pricing structure questions whether this strategy is one that only responds to the strategic interaction of an oligopolistic industry or, conversely, one established by the companies to prevent the entry of potential rivals and/or to predate smaller companies. ${ }^{1}$

This paper uses a model of strategic interaction among firms -that set discriminatory and nonlinear prices- to assess the extent to which on-net and off-net price differentials, which are explicit in the plans marketed by the three major mobile telephone companies in Chile, represent anti-competitive or predatory practices. For this purpose, we calibrate a twopart tariff network competition model for Chile with asymmetric firms that can price discriminate between on-net and off-net calls (Hoernig 2007; 2014). Then we compare the prices that would naturally emerge under competition with the actual prices offered by the three main operators (Movistar, Entel, and Claro). For this purpose, we constructed a detailed price database using information from the telecommunications regulator.

The main contribution of the paper is to calibrate a strategic competition theoretical model and then compare the predictions of the model to actual data from a mobile telephony market to evaluate the competitive effects of on-net off-net price discrimination. The empirical exercise also contributes to the policy discussion about how to proceed with the recurring allegations presented before the antitrust authorities for predatory practices and/or the introduction of artificial entry barriers in this industry in Chile. Our main result is that, in general, the observed price differentials are within the boundaries of what can be expected as equilibrium of the strategic interaction in this market. However, a small number of plans, offered by the three major mobile telephony operators in Chile, could be considered

\footnotetext{
${ }^{1}$ In this paper, we refer to predatory practices as it is done in Hoernig (2007). It is not in the AreedaTurner logic of prices below costs, but in the sense of choosing sub-optimal prices (in a static game) with the purpose of reducing competitors' profits.
} 
predatory in the sense that their price differential between off-net and on-net calls cannot be justified by cost differentials and just strategic (static) considerations.

The paper continues as follows. Section 2 reviews the main results from the literature on network competition. In Section 3 we briefly describe the Chilean mobile market. Section 4 discusses the model of Hoernig (2007) as in Section 5 we calibrate it to evaluate the extent to which observed price differentials in Chile can be considered anti-competitive. Section 6 concludes.

\section{Literature on Network Competition}

The literature on network competition starts with the seminal works of Laffont, Rey and Tirole (1998a and 1998b) -hereinafter referred to as LRT- and Armstrong (1998), which lay out the basic framework to analyze this type of markets. Their work has been followed by a myriad of papers that consider a number of alternative setups: linear vs. non-linear prices, discriminatory or non-discriminatory prices (on-net/off-net), symmetric vs. asymmetric networks, considering or ignoring call externalities, homogeneous or heterogeneous consumers, balanced call pattern vs. the formation of clubs within networks, and, more recently, distinguishing between passive vs. responsive expectations for consumers.

Beyond the analysis of optimal price setting by the firms, the main issue addressed by this literature is the regulation of access charges and the extent to which they can be used as a collusive device if left unregulated. In the case of discriminatory prices, the literature has focused on two issues. First, on the incentives that firms have to price discriminate between on-net and off-net calls -particularly when call externalities are considered- and when it could have anti-competitive effects. Second, how the incentives generated by the access charge regulation may differ between larger and smaller firms (or potential entrants). We briefly discuss here the main results in this literature to provide a general context for the model we then calibrate.

LRT (1998b) analyze the case of linear but discriminatory pricing, finding that the socially optimal reciprocal access charge is less than the marginal cost of terminating calls. However, this access charge would be set above marginal cost if left to the companies. The authors show that in equilibrium the gap between on-net and off-net prices and the average price level are both increasing with the access charge. Therefore, as in the simpler case of nondiscriminatory prices (LRT, 1998a; Armstrong, 1998), the access charge can be used as an 
instrument to collude. Furthermore, LRT (1998b) show that if access charges are set above marginal cost -whether set by the regulator or the companies-, then price discrimination between on-net and off-net calls is desirable from a social point of view since it leads to lower prices.

In the case of non-linear and non-discriminatory prices, LRT (1998b) show that access charges have no incidence on firms' profits: any increase in access charges that leads to an increase in the variable price intensifies ex-ante competition, so the effect is exactly compensated by lower fixed charges. Firms set the variable price equal to the perceived marginal cost and, therefore, social welfare is maximized when access charges equal access cost. Hahn (2004) extends this result to the case of heterogeneous consumers and asymmetric information. Carter and Wright (2003) show that, in the case of asymmetric networks, the larger network always has incentives to set access charges equal to its marginal cost. Dessein (2003) shows that profits remain independent of access charges when consumers are heterogeneous and firms engage in second degree price discrimination.

Valetti and Cambini (2005) challenge the access-charge-profit-neutrality result. They show that if firms have to invest in the quality of the networks before choosing prices, then they will prefer access charges above the marginal cost of call terminations. Access charges above costs are thus used as a commitment mechanism to reduce the quality of the networks since the better-quality network subscribers will originate more calls and produce an access deficit. This result also applies to the case where there are linear but discriminatory prices between on-net and off-net calls (Cambini and Valetti, 2003).

In the case of non-linear and discriminatory prices, Gans and King (2001) show that firms' incentive is to agree on a below cost access charge. In this case, off-net prices would be lower than on-net prices and consumers will prefer to subscribe to the smaller network, softening the competition for subscribers. The result is reversed, however, if consumers face significant switching costs when changing between networks and mainly place calls to a reduced number of other subscribers (i.e., "friends and family clubs" are formed; Gabrielsen and Vagstad, 2008 and Hoernig et al., 2014), or if incumbent networks want to deter potential entry (Calzada and Valletti, 2008 and López and Rey, 2012). Hurkens and López (2014) also find that profits are increasing with access charges when the subscriber's expectations about networks sizes are passive rather than responsive to non-equilibrium prices.

A key contribution to this literature is DeGraba (2003), who introduces call externalities: a call generates a positive externality to the receiver. Hence, the call is not only 
valuable to the caller -who bears the cost under "calling party pays" regimes- but also to the receiver. Berger (2004) makes the same assumption. Both authors find that, in the case of linear discriminatory prices, the optimal access charge -jointly chosen by the firms- is below the marginal cost of terminating a call, but it is higher than the socially optimal charge. Even though the "bill and keep" scheme (i.e., access charge equal to zero) is not necessarily optimal for Berger (2004), it would be more in line with the socially optimal than setting the access charges at the marginal cost of call terminations.

In the case of non-linear and discriminatory prices, Berger (2005) shows that firms choose on-net prices at the efficient level (i.e., below costs, fully internalizing the externality) and off-net prices above costs. Setting on-net prices at the efficient level maximizes the surplus for its subscribers, while firm profits are maximized through a higher fixed charge. The off-net price is set above the efficient level since the firm does not internalize the call externality for off-net calls. Consistent with DeGraba (2003) and Berger (2004), Armstrong and Wright (2007) found that if it were possible for operators to jointly choose access charges, they would opt for an access charge below the marginal cost (but above the socially optimal level). The reason why competitors would jointly choose access charges below cost is that higher access charges make off-net calls more expensive than on-net calls and, hence, users will prefer to remain with networks that have more subscribers. This, in turn, intensifies the competition for customers. Conversely, if the operators can set lower termination charges, then users will opt for smaller networks, softening the competition for subscribers (Harbord and Pagnozzi, 2010).

Finally, Hoernig (2007) shows that with ex-ante asymmetric networks, the larger one has an additional incentive to increase off-net prices to make the small network less attractive, as its subscribers will receive fewer calls from the larger network.

\section{The Mobile Telecommunications Industry in Chile}

The mobile industry in Chile has grown significantly in the past 15 years, since the change in regulations that set tariffs according to the "calling party pays" system in 1999. The prepaid option was introduced almost simultaneously, making it possible for the mobile telephone services to reach the poorest segments of the population. As a result, the increase in penetration has been steadily increasing from $20 \%$ in 2000 to nearly $118 \%$ in 2011. 
For several years there were four competitors in the industry (Telefonica, Entel, Smartcom, and Bellsouth), but since the acquisition of Bellsouth by Movistar in 2006, there have been until today only three large firms in the market: Movistar (owned by Telefonica), Entel, and Claro (entered the market in 2006 buying Smartcom). The first two have a share of $41 \%$ and $37 \%$, respectively, while Claro maintains a market share of almost $23 \% .^{2}$

Since the beginning of the mobile industry in Chile in the early nineties, the companies have been free to set final prices because the antitrust authority has always considered it as a competitive market. However, the mobile access charges (or termination rates) are determined by the telecommunications regulatory authority every five years with a costbased logic.

Despite the steep growth of the mobile penetration rate, the Chilean market is still comprised of a significant proportion of prepaid users (around 71\% of total users who originate around $44 \%$ of total traffic in 2011). Consumers face a large variety of prices: if they choose a pre-paid plan, they face linear prices that may discriminate between on-net and offnet calls; if they choose a post-paid plan, then the number of different tariffs is much larger, as a single plan involves a fixed fee, the quantity of on-net and off-net "free" minutes included in the fixed fee, and marginal prices for on-net and off-net minutes in excess of those included.

In the last few years, the discussion about on-net and off-net price differentials has heated up in the public debate. This debate has also been fueled by the access charge regulation, as in this process larger firms have an incentive to report larger costs so as to induce a higher access charge ${ }^{3}$ and it has been argued that the differential is in part explained by access charges above costs. In fact, the Competition Court (Tribunal de Defensa de la Libre Competencia) analyzed the situation in 2012 and determined that the firms could no longer set different tariffs for on-net and off-net calls and gave them two years to adjust the plans they offer.

In the next sections, we present and calibrate Hoernig's (2007) model to evaluate whether the observed firms' price differentials could be explained by competitive factors or whether they should be considered as anti-competitive.

\footnotetext{
${ }^{2}$ There are also a few small virtual operator companies that have recently entered the market and that together accounted for less than 1\% of the market in 2011.

${ }^{3}$ For example, the values of the so-called "efficient" costs presented by the three companies in their tariff studies for the year 2014 were approximately US $\$ 0.102$ per minute for Movistar, US $\$ 0.057$ for Entel PCS, and US\$0.03 for Claro.
} 


\section{A Simple Calibrated Model}

In this section we present a service differentiation Hotelling type of model characterized by competition among asymmetric networks, with call externalities and (nonlinear) discriminatory prices, which can then be calibrated using public information from the telecommunications regulator in Chile. For this purpose, we rely on the work of Hoernig (2007, 2014), who extends the models developed by Berger (2004 and 2005) and by Jeon, Laffont and Tirole (2004). We first present a simpler version of the model with just two firms and then we discuss how it is extended to three or more networks following Hoernig (2014). Our focus is on the results with non-linear tariffs, which is the most relevant for Chile.

\subsection{The Basic Model}

Two firms (0 and 1) are located at the extreme points of the interval [0,1], respectively. Each firm has a fixed cost $\phi_{\mathrm{i}}$, a fixed cost per client $f_{i}$, a cost per minute of calls originating from its network $c_{o, i}$, a cost for terminating calls on its own network $c_{t, i}$, and a cost for terminating calls on the rival network $a_{j}$ that is equal to the access charge set by the regulator. Thus, the marginal cost to the firm of an on-net call is $c_{i i}=c_{0, i}+c_{t, i}$, while that of an off-net call is $c_{i j}=c_{0, i}$ $+a_{j}$. The proportion of subscribers of the firm $i$ is denoted by $\alpha_{i}$ and depends on the prices chosen by both firms. The price of calls originated within the network $i$ and terminated on the network $j$ is denoted by $p_{i, j}(i, j=0,1)$. Additionally, in the case of non-linear tariffs, firm $i$ charges to its customers a flat price equal to $F_{i}$.

The model considers that there is a unit mass of consumers uniformly distributed in the interval $[0,1]$. Individuals receive a utility equal to $u(q)$ for calls placed, where $q$ is the length of the calls. To obtain analytical results, a demand with constant price elasticity is assumed: $q(p)=p^{-\eta}$, where $\eta>1$ is the demand elasticity. Additionally, it is assumed that individuals obtain a utility $\gamma(q)$ for each call received, where $0<\gamma<1$, and a utility $v_{0}$ for being subscribed to one of the networks. This value is assumed to be large enough so that in equilibrium all consumers subscribe to a network. As is standard in Hotelling type models, an individual located at position $x$ receives a disutility proportional to the distance from the subscribed network. Thus, if an individual x subscribes to the network 0 then the disutility will be $x / 2 \sigma$ and if he subscribes to the network 1 then the disutility will be $(1-x) / 2 \sigma$, where $1 / \sigma$ is the transportation cost. Asymmetry among networks is introduced by assuming that consumers obtain an extra utility, denoted by $\beta>0$, for subscribing to the network 0 . 
Naturally, the proposed model makes it possible to replicate the results of LRT (1998a) by setting the parameters $\beta=\gamma=0$.

A first step in the analysis is to identify the market share that each firm captures as a function of prices, for which it is necessary to identify the consumer who is indifferent to subscribing to any of the networks. Thus, an individual $x$, who is indifferent between subscribing to any of the two networks, receives the same utility, which is true for:

$$
x^{*}=\alpha_{0}=\frac{\frac{1}{2}+A+\sigma\left(h_{01}-h_{11}-F_{0}+F_{1}\right)}{1+\sigma\left(h_{01}+h_{10}-h_{00}-h_{11}\right)}=\frac{H_{0}}{H}
$$

where $A=\beta \sigma, h_{i j}=v\left(p_{i j}\right)+\gamma u\left(q_{i j}\right)$

Consequently, the profits for each firm will be:

$$
\begin{aligned}
& \pi_{0}=\alpha_{0}\left[\alpha_{0}\left(p_{00}-c_{00}\right) q_{00}+\alpha_{1}\left(p_{01}-c_{01}\right) q_{01}+F_{0}-f_{0}+\alpha_{1}\left(a_{0}-c_{t, 0}\right) q_{10}\right\rfloor-\phi_{0} \\
& \pi_{1}=\alpha_{1}\left[\alpha_{1}\left(p_{11}-c_{11}\right) q_{11}+\alpha_{0}\left(p_{10}-c_{10}\right) q_{10}+F_{1}-f_{1}+\alpha_{0}\left(a_{1}-c_{t, 1}\right) q_{01}\right]-\phi_{1} .
\end{aligned}
$$

In terms of economic efficiency, note that the fact that a subscriber to the network $i$ makes $q_{i i}$ calls generates a utility equal to $u\left(q_{i i}\right)(1+\gamma)$-due to the presence of the externalityand a cost equal to $q_{i i} c_{i i}$, so that the socially optimal number of calls is defined as $q_{i i}^{*}: u^{\prime}\left(q_{i i}^{*}\right)(1+\gamma)=c_{i i}$. Therefore, in order to obtain this optimal number of calls, the prices of on-net and off-net calls should be less than the marginal costs:

$$
p_{i i}^{*}=\frac{c_{i i}}{1+\gamma} ; p_{i j}^{*}=\frac{c_{i j}}{1+\gamma} \text {. }
$$

Given these prices and assuming symmetric costs among firms, the socially optimal market shares are given by $\alpha_{0}=1 / 2+A$ (logically, given the call prices, the access charges and the fixed prices are irrelevant for total welfare, as they represent mere money transfers between agents).

As we seek equilibria in a model in which firms engage in termination-based price discrimination and nonlinear pricing, we must distinguish between the results obtained with symmetric and asymmetric networks. It is easier to obtain the equilibrium in any of these two cases than in models of non-linear pricing since the introduction of the fixed charge, which includes call minutes available at no extra cost, allows firms to set on-net and off-net call prices such that its network becomes more attractive than the rival network. Hence, the fixed charge makes it possible to recover any losses that traffic might generate. In particular, the competitors are able to internalize the externality generated by on-net calls, and thus, set an 
efficient price for them; and the profits for increasing their own network's attractiveness is captured by charging a higher fixed tariff. This possibility is obviously not feasible for the rival network subscribers and, therefore, the incentive to internalize the externality with respect to off-net calls disappears. Moreover, firms have an incentive to increase the price of off-net calls beyond its cost, in order to make subscription to the rival network less attractive as its subscribers would receive less calls. Naturally, this effect is larger the more important the call externality is.

When symmetrical networks are considered, the different on-net and off-net prices and fixed charge (in symmetric equilibrium) that arise in these stages are: 4

$$
p_{i i}=\frac{c_{i i}}{1+\gamma} ; p_{i j}=\frac{c_{i j}}{1-\gamma} ; F_{i}=f_{i}+\frac{H}{2 \sigma}+\left(c_{i i}-p_{i i}\right) q_{i i} .
$$

Therefore, in the strategic interaction equilibrium, the price of off-net calls exceeds its marginal cost (and obviously the socially efficient level), while the price of on-net calls is socially efficient. The optimal fixed price makes it possible to recover the losses generated by on-net calls that are priced below marginal cost. Note that the price differential between offnet and on-net calls can be written as:

$$
p_{i j}-p_{i i}=\left(\frac{c_{i j}}{1-\gamma}-c_{i j}\right)+\left(a_{j}-c_{t, i}\right)+\left(c_{i i}-\frac{c_{i i}}{1+\gamma}\right)
$$

The intuition behind this formula is discussed in the context of three or more firms in the following subsection.

\subsection{The Model with three or more asymmetric firms}

To calibrate the model parameters using Chilean data it is necessary to consider the case of three firms and allow for firm asymmetries. Armstrong and Wright (2009) and Hoernig (2014) extend the model and find qualitatively similar results. In particular, Hoernig (2014) extends the Hotelling model assuming there are $N$ networks connected by $N(N-1) / 2$ segments in which consumers are distributed, obtaining generalizations of the previous results. In a competitive equilibrium with two part tariffs, each network will choose an efficient on-net price, while the off-net price when the access charge is reciprocal, is:

\footnotetext{
4 The derivation directly follows Berger (2005) and Jeon, Laffont and Tirole (2004). It is assumed that $\alpha_{i}>1 /(1+\gamma)$, since otherwise the off-net price cannot be determined. Formally, the process of solving the maximization problem of a firm consists of two stages. In the first stage, the optimal on-net and off-net call prices are determined given the prices of the other firm and a certain desired market share -which can be achieved by adjusting the fixed charge. In the second stage, the optimal level of market share is determined (given the prices of the other firm).
} 


$$
\boldsymbol{p}_{i j}=\frac{\boldsymbol{c}_{i j}}{1-\frac{\gamma \alpha_{i}}{\left(1-\alpha_{i}\right)}}
$$

Therefore, in a competitive equilibrium the off-net/on-net price differential can be decomposed in a way that is similar to the case of two networks:

$$
p_{i j}-p_{i i}=\left(\frac{c_{i j}}{1-\frac{\gamma \alpha_{i}}{\left(1-\alpha_{i}\right)}}-c_{i j}\right)+\left(a_{j}-c_{t, i}\right)+\left(c_{i i}-\frac{c_{i i}}{1+\gamma}\right)
$$

This expression can be compared with information on the existing plans of Entel, Claro and Movistar. ${ }^{5}$

\subsection{Discussion}

The on-net/off-net price differential, which is synthesized in equation (2), can be explained by three conceptually different elements. The first and most obvious element is related to the difference that may exist between the cost of terminating a call on a firm's own network and the one of terminating it on another firm's network. This latter value is given by the "access charge" and is regulated. An imperfect regulation, in which the access charge is set above marginal cost, partly explains the observed price differential (second term in equation 2).

The second and third elements are related to the existence of call externalities and the use of two-part tariffs. On the one hand, given the "calling party pays" regulation, the firm has an incentive to charge an on-net price below its cost (third term in equation 2) and as a result the total number of calls made by the subscriber is socially efficient. That is, the firm internalizes the externality. The incentive to set this price exists because it is possible to "recover" the per-call loss by charging a higher fixed tariff. It is important to highlight that this is not the case of predation with short-term losses that will be recovered in the future. It is simply a two-part tariff: the variable charge is set to maximize the utility of the subscribers and the fixed charge is the competition variable that allows the recovery of the "losses" and/or extraction of the consumer surplus.

On the other hand, and this corresponds to the first term in equation 2 , since the firm is unable to charge a fixed price to non-subscribers, the off-net price should not be less than the access charge plus the cost of call origination. Furthermore, as subscribers of different

\footnotetext{
${ }^{5}$ It is important to mention that if consumers are able to internalize the call externality, or perceive that their calls generate stable relationships with other consumers through telephony the incentive to raise the price of off-net calls above cost does not disappear, but is mitigated (Cambini and Valletti, 2008).
} 
networks consider not only the price of originating a call but also the number of calls they expect to receive in its subscription decision, ${ }^{6}$ each firm has an incentive to charge off-net prices above the perceived cost, and thus reduce the rival network's attractiveness. Note also that the off-net price is larger the more important the call externality is. A larger off-net price, ceteris paribus, increases the number of subscribers.

The previous discussion is represented in Figure 1 that shows the off-net on-net price differentials that the competitive model predicts without and with positive externalities respectively. In the former, the price differential should be equal to the difference between the access charge and the marginal call termination cost. In the latter, the competitive price differential is larger as firms have an incentive to lower the on-net price to internalize the externality and to increase the off-net price. Any price differential larger than the one associated to the effects of the positive externality and the access charge above cost can be associate to potentially anticompetitive practices.

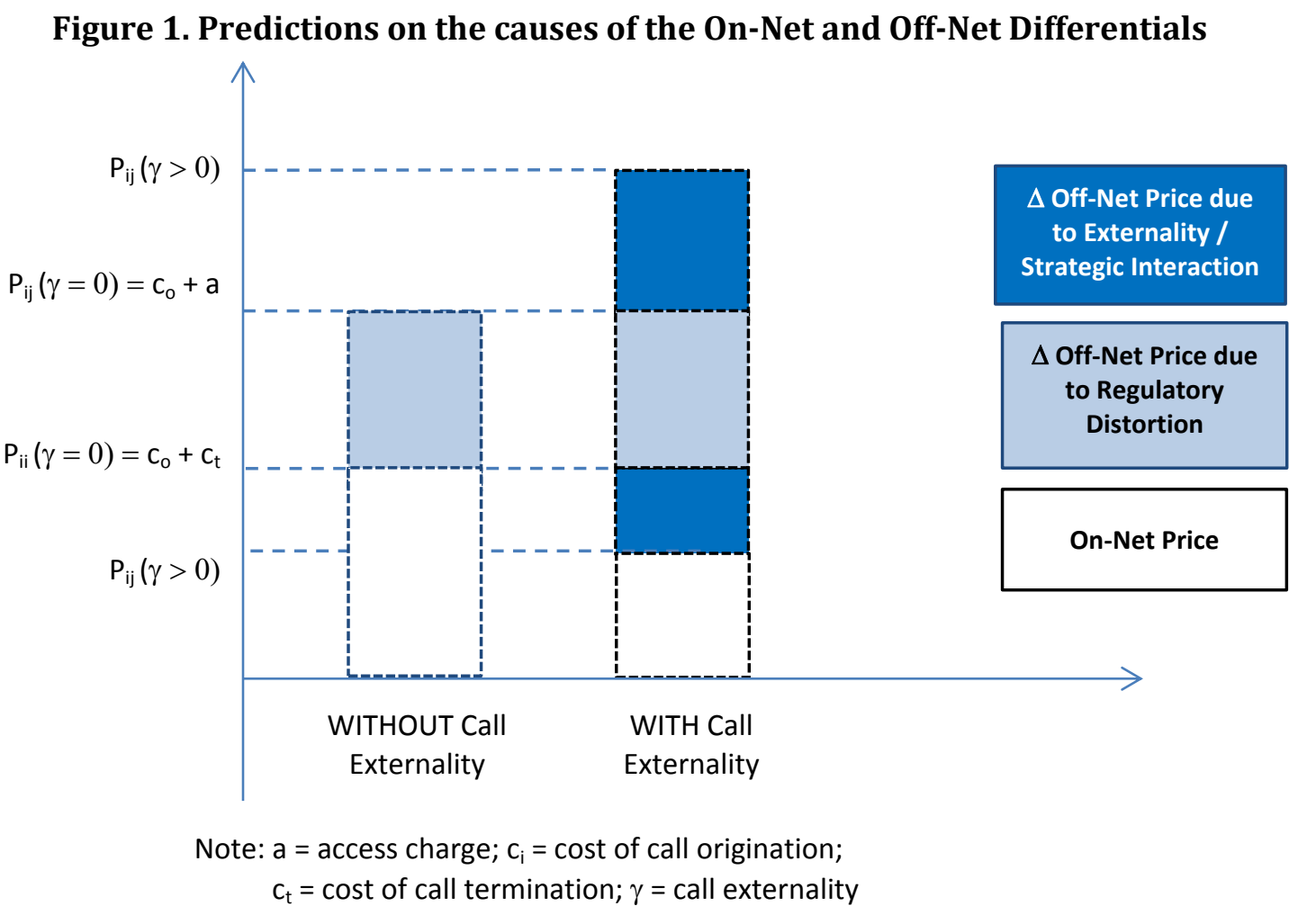

Source: Authors' elaboration.

\footnotetext{
${ }^{6}$ Obviously, total calls received depend both on the on-net price of the chosen network and on the offnet price of the other networks.
} 
Clearly, from an antitrust perspective, the first two elements that explain the price differential cannot be challenged as being anticompetitive (terms 2 and 3 in equation 2). The third element -the incentive to increase the price of off-net calls to make the rival networks less attractive- seems to be more controversial. In terms of the theoretical model presented, there are no arguments related to predation or to a strategy that seeks to prevent entry when prices are set according to (2). Moreover, there is no profit sacrifice as long as the price differential is fully explained by the three terms in equation (2).

However, as Hoernig (2007) points out, if a firm were to sacrifice current profits to decrease rival's profits, then it would be more optimal to maintain the efficient on-net price, increasing the off-net price, and reducing the fixed charge. Therefore, price differentials above those that can be explained by equation (2) could be considered predatory.

Based on the above arguments and formula (2), we calculate a price differential threshold for each firm. Price differentials above the threshold should worry competition authorities, as a possible explanation could be an anticompetitive behavior such as predation.

\section{Empirical Analysis of the Existing Plans}

For the empirical analysis we use data from the telecommunications regulatory agency (SUBTEL) that has the prices of all commercially available plans for the three main companies in March 2011. The database contained the details of all of the 202 different plans offered by the three firms: 93 by Movistar, 51 by Entel PCS, and 58 by Claro. In order to verify whether discriminatory pricing is or is not anti-competitive, it is important to clarify that the database only contains prices of contract-based plans.

As previously mentioned, price discrimination can be analyzed in two different but complimentary dimensions. For a fixed monthly fee, plans may offer a number of "free" minutes that could vary according to the call destination, so there is a difference on the implicit average per-minute price. They may also include marginal prices (that become relevant once the free minutes are exhausted) that differ for on-net and off-net calls. We analyze the two dimensions.

Marginal prices are directly observable since they are explicit in all plans. The average price of included on-net and off-net minutes are not explicitly defined in the plans, but they can be derived from the fixed charge and the number of on-net and off-net minutes included. For this purpose we make two reasonable assumptions. First, customers exhaust all included 
minutes (therefore the fixed charge equals the sum of the number of the included minutes times their corresponding price). Second, relative on-net off-net prices are equal to the inverse of the number of minutes included. These assumptions pin down the two prices.

Table 1 reports the number of plans offered by each firm separated between discriminatory and non-discriminatory ones and also by type of discrimination. As can be seen from the table, there are 202 different plans and only $43(21.3 \%)$ price discriminate in some form. Among the plans offered by Movistar, 23\% price discriminate on both the average and the marginal price. In the case of Claro $9 \%$ of the plans discriminate on the two dimensions. Claro and Movistar do not have any plans that discriminate only on one dimension. In the case of Entel, $37 \%$ of the total number of plans involve some discrimination; about $74 \%$ of these discriminate on both dimensions while the rest do it only on the marginal price. $^{7}$

Table 1: Number of Plans

\begin{tabular}{|c|c|c|c|c|c|c|}
\hline & \multirow{2}{*}{$\begin{array}{c}\text { Total } \\
\text { Number of } \\
\text { Plans }\end{array}$} & \multirow{2}{*}{$\begin{array}{l}\text { Non- } \\
\text { discriminatory } \\
\text { plans }\end{array}$} & \multicolumn{4}{|c|}{ Discriminatory plans } \\
\hline & & & Total & $\begin{array}{l}\text { Only on } \\
\text { Average } \\
\text { Price } \\
\end{array}$ & $\begin{array}{c}\text { Only on } \\
\text { Marginal } \\
\text { Price }\end{array}$ & On Both \\
\hline Movistar & 93 & 72 & 21 & 0 & 0 & 21 \\
\hline Claro & 58 & 53 & 5 & 0 & 0 & 5 \\
\hline Entel & 51 & 34 & 17 & 0 & 11 & 6 \\
\hline Total & 202 & 159 & 43 & $\mathbf{0}$ & 11 & 32 \\
\hline
\end{tabular}

Source: Own calculations.

The discrimination on average prices ranges from $\operatorname{Ch} \$ 118$ (US $\$ 0.24$ ) to $\operatorname{Ch} \$ 324$ (US\$0.66) per minute. ${ }^{8}$ As shown in Table 2, Movistar is the firm with the largest price differential and Claro the one with the smallest.

Marginal price discrimination, as can be seen on Table 3, is less severe as it ranges from $\operatorname{Ch} \$ 50$ (US\$0.1) to Ch\$141 (US\$0.29). In this case it is Entel the firm that has not only the largest fraction of marginal-discriminatory plans, but it also the one with largest price differentials on average.

\footnotetext{
${ }^{7}$ Although both types of price discrimination may be relevant depending on the plan and the use patterns of different consumers, mean-price discrimination may be more relevant as all customers first make use of the free minutes. Agostini et al (2016) also report that Movistar customers on average do not exceed the number of "free" minutes included in their plans.

${ }^{8}$ All figures are in Chilean pesos. In 2011, the average exchange rate was 490 Chilean pesos to 1 US dollar.
} 
Table 2: Mean-price differentials by firm

(only plans that discriminate on mean price)

\begin{tabular}{|c|c|c|c|}
\hline & $\begin{array}{c}\text { Minimum price } \\
\text { differential }\end{array}$ & $\begin{array}{c}\text { Average price } \\
\text { differential }\end{array}$ & $\begin{array}{c}\text { Maximum price } \\
\text { differential }\end{array}$ \\
\hline Movistar & 118 & 195 & 324 \\
\hline Claro & 124 & 152 & 183 \\
\hline Entel & 122 & 181 & 307 \\
\hline Total & $\mathbf{1 1 8}$ & $\mathbf{1 8 6}$ & $\mathbf{3 2 4}$ \\
\hline
\end{tabular}

Source: Own calculations.

Table 3: Marginal-price differentials by firm

(only plans that discriminate on marginal price)

\begin{tabular}{|c|c|c|c|}
\hline & $\begin{array}{c}\text { Minimum price } \\
\text { differential }\end{array}$ & $\begin{array}{c}\text { Average price } \\
\text { differential }\end{array}$ & $\begin{array}{c}\text { Maximum price } \\
\text { differential }\end{array}$ \\
\hline Movistar & 50 & 89 & 141 \\
\hline Claro & 75 & 88 & 105 \\
\hline Entel & 80 & 103 & 135 \\
\hline Total & $\mathbf{5 0}$ & $\mathbf{9 5}$ & $\mathbf{1 4 1}$ \\
\hline
\end{tabular}

Source: Own calculations.

With the purpose of doing a statistical analysis of the price discrimination between onnet and off-net prices, we use Kernel distribution to estimate the density distribution of the price differentials (mean and marginal). The results are presented in Figure 2 for the subset of mean-discriminatory plans and on Figure 3 for those that discriminate on marginal prices. 
Figure 2. Mean Price Differential Estimated Density Distributions (mean-discriminatory plans, by firm)

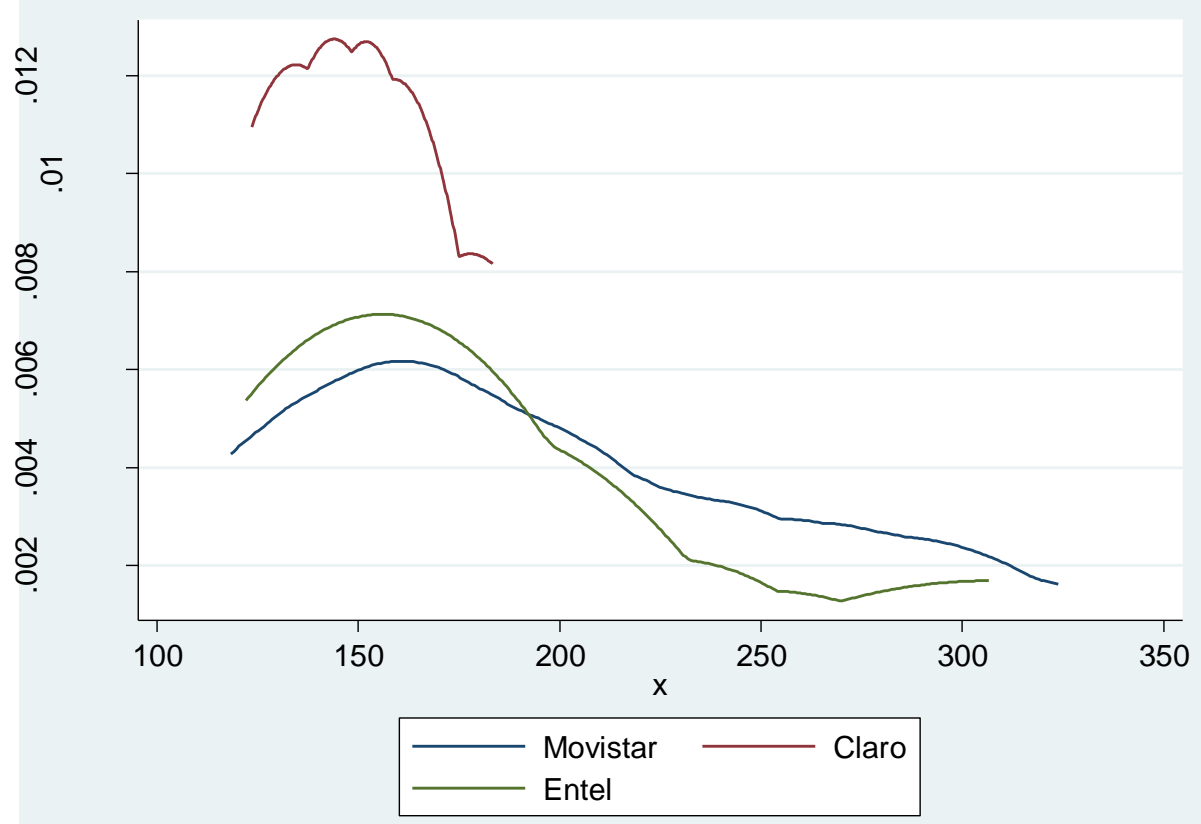

Source: Authors' calculations.

Figure 3. Marginal Price Differential Estimated Density Distributions

(marginal-discriminatory plans, by firm)

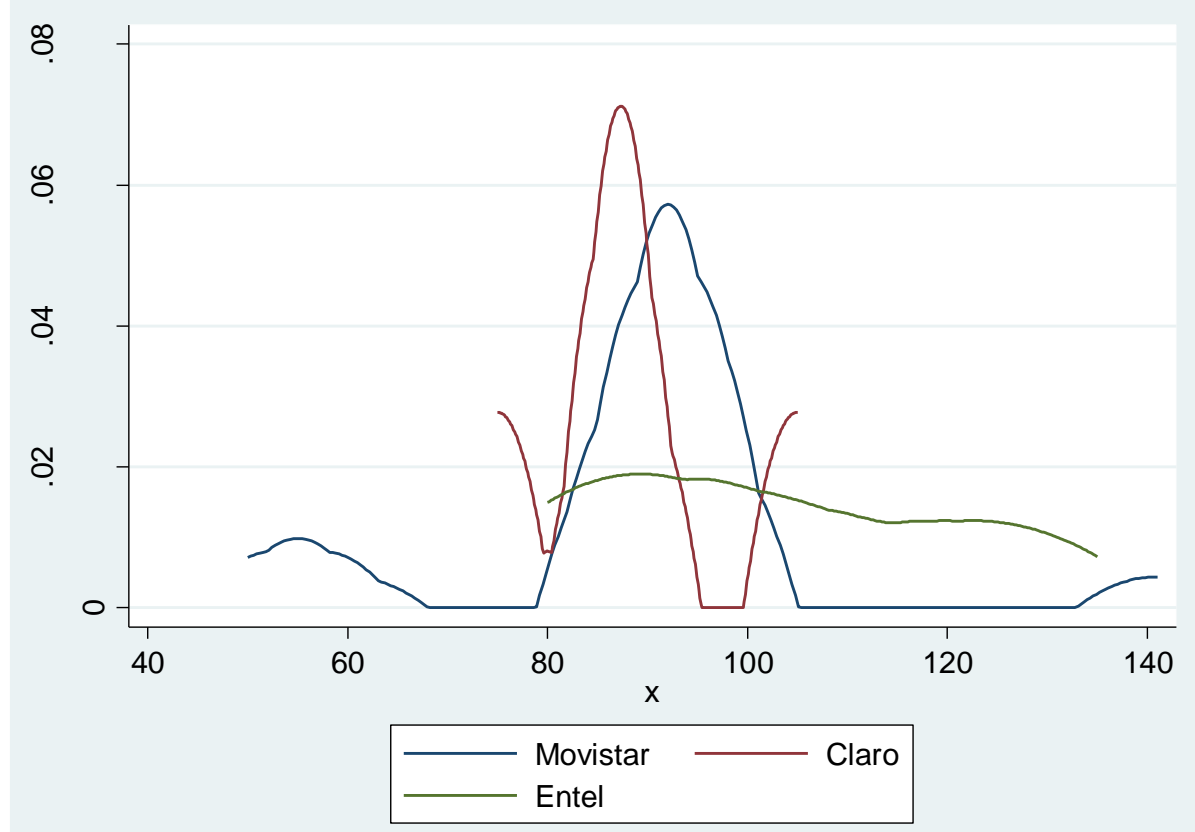

Source: Authors' calculations. 
As it is clear from the two figures, the larger firms are the ones that more heavily discriminate. In the more relevant case of mean-price discrimination, it is the largest firm (Movistar) the one that more severely discriminates and Claro, the smallest one, is the one that discriminates the least. Notice that this is true not only if we consider the average of the off-net/on-net price differential of the plans that discriminate (Table 2), but also if we take into account the fraction of plans that do discriminate for each firm (Table 1).

These results are consistent both with the theory that the largest networks tend to engage in predatory behavior in this market, as well as with the theory that this is the most reasonable result for strategic interaction among these companies. In order to clarify this point, these values are compared in the next section with the thresholds obtained for each company from equation (2).

\section{Results}

A competitive equilibrium for the on-net/off-net price differentials can be calculated from the costs of each firm, the value of the externality, and the access charge and market share of each firm. These values can then be compared to the actual price differentials observed in the market.

As in most of the literature, it is assumed that the values of originating and terminating calls are identical. Therefore, the cost of an on-net call for network $i$ is simply $c_{i i}=2 c_{t i}$, and the cost of an off-net call is $c_{i j}=c_{t i}+a$, where " $a$ " corresponds to the reciprocal access charge.

While the access charge " $a$ " is determined by the regulator and, therefore, easily observable, the cost of originating or terminating a call is not. During the regulatory processes to set access charges, the companies submit their cost studies and present their "efficient costs" that correspond to the costs of a hypothetical efficient firm designed by each operator using the best technology available. These costs cover the investment, operational, and expansion costs of the project. Table 4 shows the values presented by the mobile telephone companies in the regulatory processes for the periods 2009-2014 and 2014-2019. 
Table 4. Efficient Tariff Rates presented by Mobile Telephone Companies

(the 2009-2014 and the 2014-2019 regulatory processes)

\begin{tabular}{|c|c|c|c|c|c|c|}
\hline \multirow{2}{*}{} & \multicolumn{3}{|c|}{ 2009-2014 } & \multicolumn{4}{c|}{ 2014-2019 } \\
\cline { 2 - 7 } & Movistar & Claro & Entel & Movistar & Claro & Entel \\
\hline Normal & 49.07 & 14.66 & 27.44 & 44.83 & 36.53 & 35.28 \\
\hline Reduced & 36.80 & 11.28 & - & 33.62 & 27.40 & 26.46 \\
\hline Night & 24.54 & 7.33 & 13.72 & 22.42 & 18.26 & 17.64 \\
\hline Weighted Average & $\mathbf{4 5 . 3 9}$ & $\mathbf{1 3 . 6 2}$ & - & $\mathbf{4 1 . 4 7}$ & $\mathbf{3 3 . 7 9}$ & $\mathbf{3 2 . 6 3}$ \\
\hline
\end{tabular}

Source: Mobile telephone company tariff studies.

There are significant differences in the "efficient" costs of the three companies. Due to the incentives that exist in the regulatory process and the pervasive information asymmetries, it is unlikely that the costs presented by the companies are the actual costs or the costs of an efficient firm. Larger companies have incentives to induce the regulator to set higher access charges so that the on-net/off-net differential is as large as possible; thus, hindering the entry and growth of potential rivals and current small rivals. This is reflected in Table 4.

Moreover, the cost calculated by the firms (and the regulator) is conceptually different from the notion of (short run) marginal cost in the theoretical model $c_{i i}$, as those presented by the firms include investment costs that do not affect the short run marginal cost. ${ }^{9}$ We do, therefore, perform a sensitivity analysis over the value of $c_{i i}$ and assume it ranges from zero to the value of the access charge " $a$ " -determined in the last regulatory process (2014-2019)-, which can be considered as an upper bound to the 'true' value of originating/terminating a call.

Table 5 shows the reciprocal access charges set by the regulator, distinguishing between three different times of the day and the weighted average (weighted by the call volumes). ${ }^{10}$

\footnotetext{
${ }^{9}$ See Harbord and Hoernig (2013) for a discussion on this issue. Regulatory processes typically use fully allocated costs models such as LRIC or LRIC+. The underlying logic of these models is that costs that are not traffic sensitive must be recovered with revenues associated to the traffic. This is clearly inefficient. According to Harbord and Hoernig (2013), costs that are sensitive to traffic in the short run are near zero.

${ }^{10}$ The traffic distributions in various tariff studies and other studies presented by smaller companies to the Competition Court (Tribunal de Defensa de la Libre Competencia) show that around $75 \%$ of all minutes occur during normal hours, $20 \%$ during reduced-rate hours, and 5\% at nighttime.
} 
Table 5. Access Charges set for the Mobile Telephone Companies

(the 2009-2014 and the 2014-2019 processes)

\begin{tabular}{|c|c|c|}
\hline & $\begin{array}{c}\text { Access Charge 2009-2014 } \\
\text { (Ch\$/minute; Ch\$ at March 2011) }\end{array}$ & $\begin{array}{c}\text { Access Charge 2014-2019 } \\
\text { (Ch\$/minute; Ch\$ at January 2014) }\end{array}$ \\
\hline Normal & 74.75 & 15.37 \\
\hline Reduced & 56.06 & 11.53 \\
\hline Night & 37.38 & 7.69 \\
\hline Weighted Average & $\mathbf{7 1 . 9 5}$ & $\mathbf{1 4 . 7 9}$ \\
\hline
\end{tabular}

Source: Authors' calculations based on the Regulatory Prices Decree.

The value of the positive externality it is critical for the calibration of the model. Ideally it would be just an empirical matter to determine it, but it is not easy to do such empirical work and to our knowledge there is one single estimation in the literature. Obviously there is not a single true value. Even for a single consumer, the value of the externality depends on the particular call he/she is receiving (e.g., from friends or from a sales representative). On average, however, it makes sense to assume that receiving calls is positively valued. Otherwise, customers would not pay for the complete telephone service and would instead opt for a service that only allows them to place calls and block the service of receiving calls.

According to Harbord and Hoernig (2012), it is reasonable to assume for the externality assigned to received phone calls a value, on average, greater than 0.5 . In the only empirical work we are aware of, Rojas (2015) estimates the size of the externality implementing a large stated preference choice experiment in Ecuador and concluded that the call externality is around 2/3 for on-net calls and significantly lower for off-net calls. For this reason, in our sensitivity analysis we consider values between 0.5 and 0.8 .

Finally, it is necessary to also have a measure of the market share of each company. A proxy that is usually considered reasonable for this parameter is the proportion of subscribers in each network: 40\% for Movistar, 37\% for Entel, and 23\% for Claro.

Based on these assumptions, Table 6 presents the values of the price differentials that would arise in equilibrium for the three largest mobile telephone companies in Chile. Note that these equilibrium prices are very sensitive to the size of the externality, but not that much to the cost of originating a call. 
Table 6. Off-Net/On-Net Price Differential Thresholds

(by call initiation cost -VAT included in Ch\$ at March 2011- and size of the externality)

\begin{tabular}{|c|ccc|ccc|ccc|}
\hline $\begin{array}{c}\text { Firm } \\
\text { (share) }\end{array}$ & \multicolumn{3}{|c|}{$\begin{array}{c}\text { Movistar } \\
(\mathbf{4 0 . 7} \%)\end{array}$} & \multicolumn{3}{c|}{$\begin{array}{c}\text { Entel } \\
(\mathbf{3 6 . 7} \%)\end{array}$} \\
\hline$\gamma \backslash \mathrm{c}_{\mathrm{oi}}$ & $\mathbf{0 . 0}$ & $\mathbf{8 . 8}$ & $\mathbf{1 7 . 6}$ & $\mathbf{0 . 0}$ & $\mathbf{8 . 8}$ & $\mathbf{1 7 . 6}$ & $\mathbf{0 . 0}$ & $\mathbf{8 . 8}$ & $\mathbf{1 7 . 6}$ \\
\hline 0.5 & 125.3 & 126.9 & 128.6 & 115.9 & 116.5 & 117.2 & 96.3 & 94.9 & 93.5 \\
0.6 & 139.9 & 143.8 & 147.8 & 126.2 & 128.7 & 131.2 & 99.8 & 99.4 & 99.1 \\
0.7 & 158.4 & 165.0 & 171.5 & 138.5 & 142.9 & 147.4 & 103.4 & 104.1 & 104.8 \\
0.8 & 182.5 & 192.2 & 201.9 & 153.5 & 160.1 & 166.7 & 107.4 & 109.1 & 110.8 \\
\hline
\end{tabular}

Source: Authors' calculations.

When comparing these thresholds with the probability distributions presented in Figures 2 and 3, the following results are obtained:

- In the case of Claro, all its discriminatory plans offer mean price differentials above what it could be considered competitive according to Table 6. It should be noticed, though, that Claro's discriminatory plans are less than $10 \%$ of their total number of plans offered.

- In the case of Entel the results are less clear, as they depend on the parameters of Table 6 considered. If we consider the value of the externality around 0.5 , then all Entel's mean discriminatory plans are above the competitive thresholds. However, if values of 0.7 or 0.8 are considered, between half and two-thirds of the plans could be considered anti-competitive.

- Similar conclusions emerge for Movistar considering discrimination on mean prices. Almost all plans are above the threshold if the externality value is 0.5 , while for values of 0.7 or 0.8 between $40 \%$ and two-thirds of the discriminatory plans could be considered anti-competitive.

- When we consider marginal price discrimination (Figure 3), almost all plans are below the thresholds determined in Table 6.

The results for each firm are summarized in Figures 4 to 6 . They present the mean and marginal discriminatory plans' distributions and the thresholds that correspond to each firm according to Table 6 (shaded areas). 
Figure 4. Mean and Marginal Price Differential Estimated Density Distributions and Competitive Thresholds for Movistar

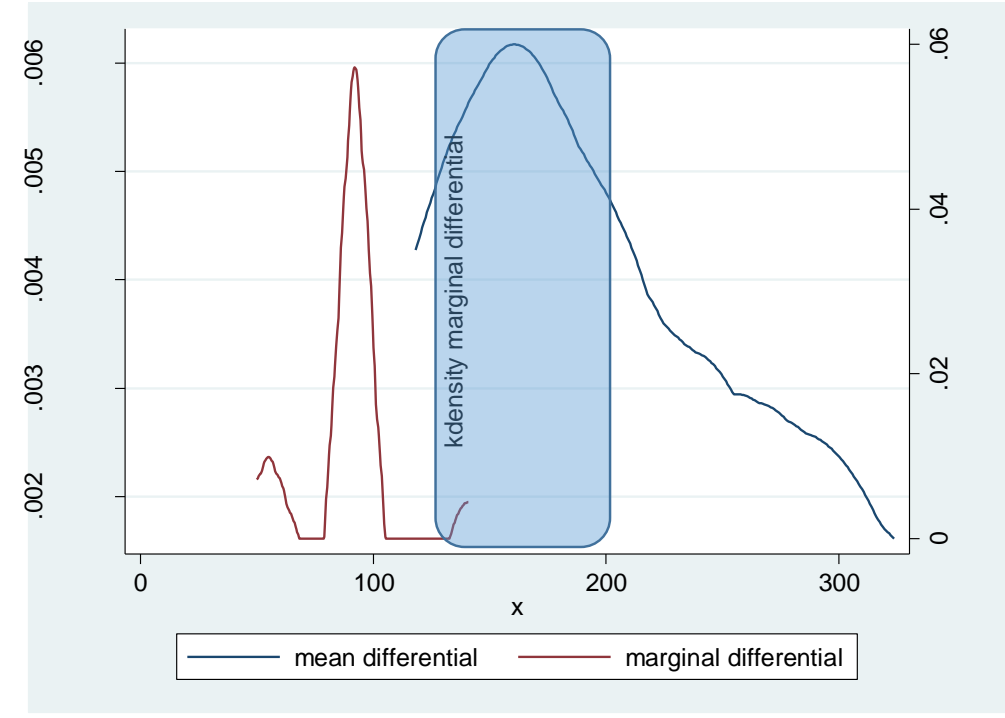

Source: Authors' calculations.

Figure 5. Mean and Marginal Price Differential Estimated Density Distributions and Competitive Thresholds for Claro

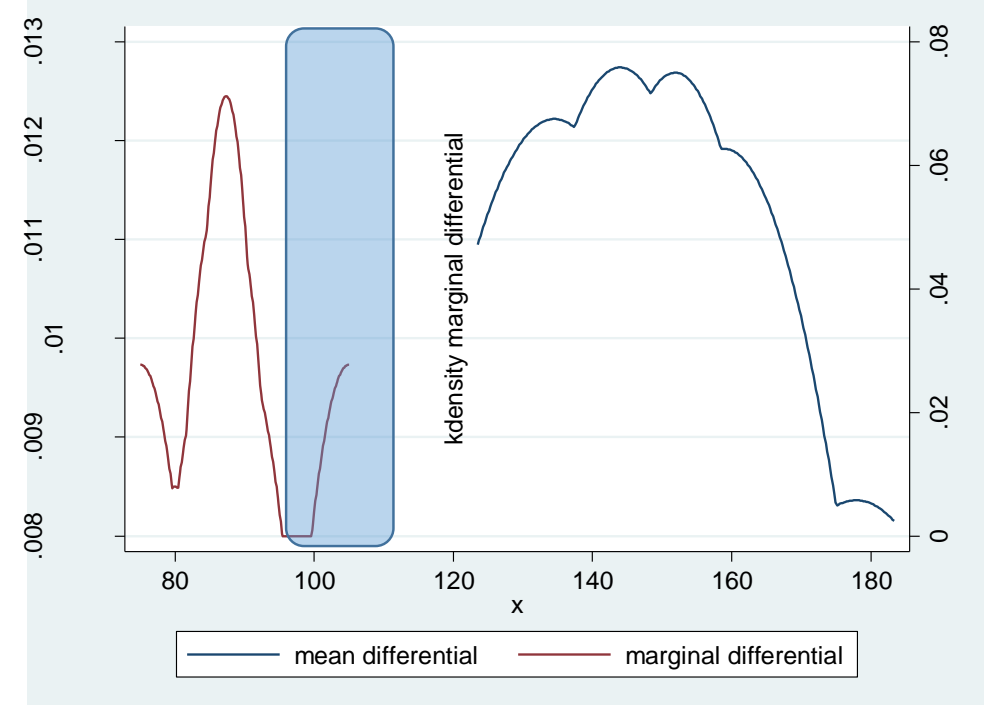

Source: Authors' calculations. 
Figure 6. Mean and Marginal Price Differential Estimated Density Distributions and Competitive Thresholds for Entel

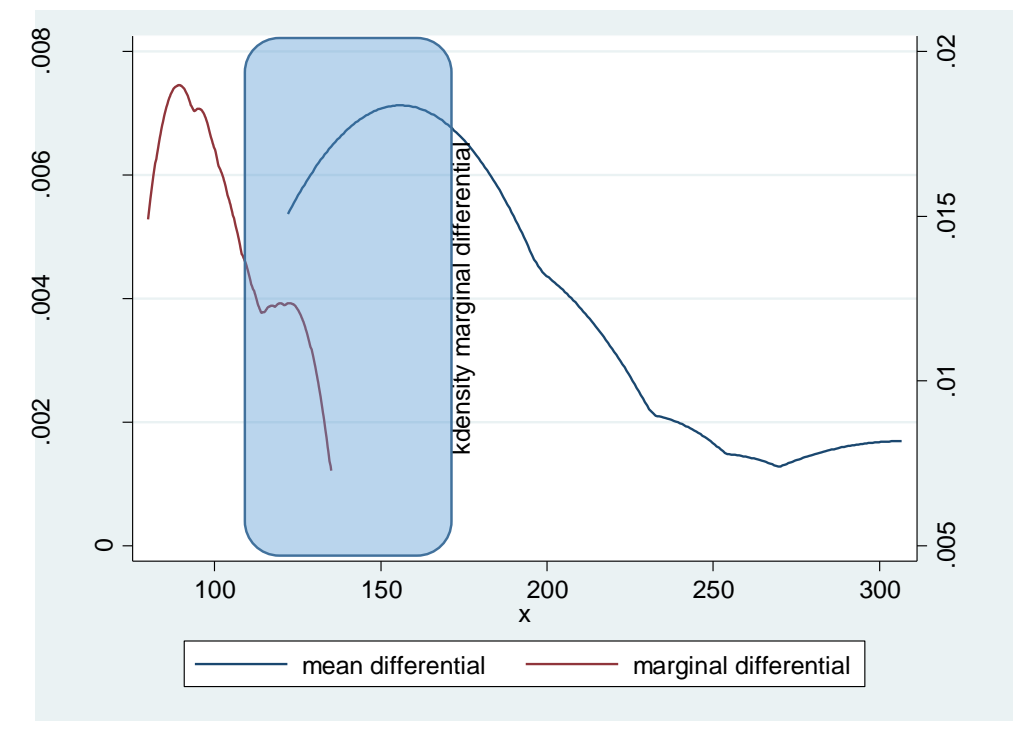

Source: Authors' calculations.

An important consideration to keep in mind is that the estimated probabilities of price differentials should ideally be weighted by traffic, as in reality the companies probably market some plans more actively than others. In fact, Agostini, Saavedra, and Willington (2016) obtain different results for Movistar when probability functions are weighted by the traffic.

\section{Conclusions}

This paper analyzes the economic rationality of the on-net and off-net price differentiation applied by the mobile telephone companies in Chile in their plans. The literature shows that the existence of price differentials between on-net and off-net calls is perfectly consistent with the strategic interaction in an oligopolistic market. The competitive arguments are twofold: i) it may be more expensive to provide the service when a call is made to another network, particularly in the case of an access charge set above the cost of terminating a call by the regulator; and ii) for reasons of strategic interaction among rival companies, it is possible to 
charge below cost for on-net calls, since its cost is recovered with the fixed charge to customers, and prices above cost for off-net calls.

However, price differentials greater than certain thresholds cannot be justified by strategic interaction and are consistent with anti-competitive strategies that seek to "softenup" smaller rival firms and/or prevent the entry of new firms. Using the results obtained from the parametrized model of Hoernig (2014), the thresholds are identified for the three mobile telephone companies, which together represent almost $100 \%$ of the market. These thresholds, which depend on the size of the call externality (assumed between 0.5 and 0.8), range from Ch $\$ 125$ to Ch\$201 per minute for Movistar (between US\$0.26 and US\$0.41), Ch\$115 to Ch $\$ 167$ per minute for Entel PCS (between US\$0.24 and US\$0.34), and $\operatorname{Ch} \$ 96$ to $\operatorname{Ch} \$ 111$ per minute for Claro (between US $\$ 0.2$ and US $\$ 0.23$ ). The price differential thresholds, which may be considered as part of the strategic interaction among the firms, differ due to two main reasons: the costs of originating and terminating calls declared by the companies in their tariff studies and the market size of each company.

When comparing the price of the discriminatory plans offered by these companies as of March 2011 with the above-mentioned thresholds, it can be seen that an important percentage of these plans are not consistent with a competitive oligopolistic market. This result supports the belief that such high on-net and off-net price differentials could be explained by anti-competitive practices: predating smaller rivals or preventing/delaying the entry of potential rivals. If we consider the more strict thresholds found, in Movistar, above $40 \%$ of its discriminatory plans can be considered predatory; in the case of Entel PCS, the proportion of predatory plans is above 50\%; and in the case of Claro the few discriminatory plans they offer are all above the competitive threshold.

Although some level of termination-based price discrimination can be justified by the strategic interaction among firms, it is important to keep in mind that in any case the resulting prices are inefficient. Hence, a question arises, beyond the scope of this paper, regarding the optimality of the Chilean regulatory framework. The price differential is a direct consequence of the access charge regulation, the calling party pays system, and the freedom to price discriminate by destination that firms enjoyed.

In 2012 the Antitrust Court deemed anti-competitive those plans that price discriminate by call destination, and gave all firms a two-year period to adjust their offers. The consequences of prohibiting price discrimination -while maintaining a CPP scheme and costbased access charge regulation- have not yet been evaluated. This is not a simple task, as 
there were other relevant changes in the same period: access charges were reduced and number portability was introduced.

From a theoretical perspective, it is apparent that the new equilibrium prices would be somewhere between the on-net and off-net prices. At least theoretically, the on-net price will no longer be efficient, while the off-net price could approach its efficient value. 


\section{References}

Agostini, C., E. Saavedra and M. Willington (2016). "Price Differentiation between On-Net and Off-Net Calls: An Application to the Chilean Telephony Market", Documento de Investigación I-313, ILADES-Universidad Alberto Hurtado.

Armstrong, M. (1998). "Network Interconnection in Telecommunications", The Economic Journal 108, pp. 545-564.

Armstrong, M. and J. Wright (2009). "Mobile Call Termination”, The Economic Journal 119, no. 538, pp. F270-F307.

Armstrong, M. and J. Wright (2007). "Two-sided Markets, Competitive Bottlenecks and Exclusive Contracts", Economic Theory 32, pp. 353-380.

Berger, U. (2004). "Access Charges in the Presence of Call Externalities", Contributions to Economic Analysis \& Policy 3.1 (2004): Article 21.

Berger, U. (2005). "Bill-and-keep vs. Cost-based Access Pricing Revisited”, Economics Letters 86, pp. 107-112.

Calzada, J. and T. Valletti (2008). "Network Competition and Entry Deterrence”, The Economic Journal 118, no. 531, pp. 1223-44.

Cambini, C. and T. Valletti (2003). "Network Competition with Price Discrimination: 'Bill and Keep' is not so Bad after all”, Economics Letters 81, pp. 205-213.

Cambini, C. and T. Valletti (2008). "Information Exchange and Competition in Communications Networks", The Journal of Industrial Economics 56, no. 4, pp. 707-28.

Carter M. and J. Wright (2003). “Asymmetric Network Interconnection.” Review of Industrial Organization 22, no. 1, pp. 27-46.

DeGraba, P. (2003). "Efficient Intercarrier Compensation for Competing Networks when Customers Share the Value of a Call”, Journal of Economics and Management Strategy 12, pp. 207-30.

Dessein, W. (2003). "Network Competition in Nonlinear Pricing", RAND Journal of Economics 34 (4), pp. 593-611.

Gabrielsen, T. and S. Vagstad (2008). "Why is On-Net Traffic Cheaper than Off-Net Traffic? Access Markup as a Collusive Device", European Economic Review 52, pp. 99-115.

Gans, J. and S. King (2001). “Using 'Bill and Keep' Interconnect Arrangements to Soften Network Competition, Economics Letters 71, pp. 413-20.

Hahn, J. (2004). "Nonlinear Pricing of Telecommunications with Call and Network Externalities", International Journal of Industrial Organization 21, pp. 949-67. 
Harbord, D. and S. Hoernig (2012). "Welfare Analysis of Regulating Mobile Termination Rates in the UK with an Application to the Orange/T-Mobile Merger", FEUNL Working Paper $\mathrm{N}^{\circ} 571$.

Harbord, D. and M. Pagnozzi (2010). “Network-based Price Discrimination and 'Bill and Keep' vs. 'Cost-based' Regulation of Mobile Termination Rates", Review of Network Economics 9(1), Article 1.

Hoernig, S. (2007). “On-Net and Off-Net Pricing on Asymmetric Telecommunications Networks", Information Economics \& Policy 19(2), pp. 171-88.

Hoernig, S. (2014). “Competition between Multiple Asymmetric Networks: Theory and Applications", International Journal of Industrial Organization 32, pp. 57-69.

Hoernig, S., R. Inderst, and T. Valletti (2014). "Calling Circles: Network Competition with Nonuniform Calling Patterns", Rand Journal of Economics 45, pp. 155-75.

Hurkens, S. and A. López (2014). "Mobile Termination, Network Externalities and Consumer Expectations." The Economic Journal 124, pp. 1005-39.

Jeon, D., J.J. Laffont and J. Tirole (2004). “On the Receiver Pays Principle”, Rand Journal of Economics 35, pp. 85-110.

Laffont, J.J., J. Tirole and P. Rey (1998a). "Network Competition: I. Overview and Nondiscriminatory Pricing", Rand Journal of Economics 29, pp. 1-37.

Laffont, J.J., J. Tirole and P. Rey (1998b). “Network Competition: II. Price Discrimination”, Rand Journal of Economics 29, pp. 38-56.

López, A. and P. Rey. (2012). "Foreclosing Competition through Access Charges and Price Discrimination", IDEI Working Paper.

Rojas, C. (2015). "How Much is an Incoming Message Worth? Estimating the Call Externality", work in progress available at SSRN: http://ssrn.com/abstract=2575167.

Valetti, T. and C. Cambini (2005). "Investments and Network Competition", Rand Journal of Economics 36, pp. 446-68. 